\section{NOTES ON THE POLLINATION OF PLUMS.}

BY L. H. PAMMEL, AMES, IOWA.

Some years ago while making a few random examinations of the cultivated DeSoto Plum (Prunus Americana, Marshall) I found to my surprise that the flowers were not all perfect, although described as such. Many flowers have since been examined and $I$ have never failed, in some individuals at least, to find this character well pronounced.

In all cases examined the suppression was in the direction of the pistil. The stamens in all cases were well developed. In these imperfect flowers the pistil is short, scarcely as long as the calyx tube. In the Rollingstone the pistil is entirely absent in many cases.

To see how generally the pistils were rudimentary, a number of counts were made on branches selected at random on several trees.

$\begin{array}{lcc} & \text { First Tree. } & \\ \text { First branch, } & \text { Perfect. } & \text { Imperfect. } \\ \text { Seeond “" } & 10 & 2 \\ \text { Third "“ } & 14 & 4 \\ \text { Fourth " } & 17 & 5 \\ & 7 & 2 \\ & \text { Second Tree. } & \\ \text { First branch, } & \text { Perfect. } & \text { Imperfect. } \\ \text { Second “" } & 15 & 2 \\ & 10 & 6 \\ \text { First branch, } & \text { Third Tree. } & \\ \text { Second "“ } & \text { Perfect. } & \text { Imperfect. }\end{array}$

These imperiect flowers also occur in the Pottawattamie, but not so commonly as the Rollingstone and DeSoto. I thought at first that these imperfect flowers might be due to the improvement of the variety under cultivation, but on examining some seedlings along an old fence I found that imperfect flowers also occurred. Of the enormous number of perfect flowers produced on a single tree a small percentage only develop into plums. They are undoubtedly in many cases fertilized but for want of nutrition fail to mature.

The flowers of Prunus Americana, in absence of cross pollination, are undoubtedly close pollinated. To test the matter of close fertilization, about 150 flowers were corered with paper bags. Of these fifty set. Between twenty-five and thirty flowers were castrated and pollen applied from other flowers of the same plant with the result that one-third set. Considering the circumstances under which they were made it is a fairly good showing.

I was much interested this spring to notice that some forms of Prunus domestica (Moldavka Plum) are proterogynous. The pistil in some cases protrudes while the flowers are still more or less closed. In other forms of Prunus domestica grown on the college grounds the pistil matures simultaneously with the stamens. This latter condition agrees with Hermann Müller's ${ }^{1}$ observations, who says of Prunus domestica, $P$. avium and $P$. cerasus, "anthers and stigmas ripen simultaneously and spread apart out of the flower." Prunus padus, L, and P. spinosa, L, according to the same authority, are proterogynous.

The Rosacece constitute an interesting order of plants, although many of them show adaptations for cross-pollination, they may, at the same time, in absence of cross-pollination, be self-pollinated, not, however, in all cases. Strawberry growers are only too familiar with the failure that results when only one variety is set out.

This tendency to separation of sexes is well marked in widely separated orders and has been admirably discussed by Darwin," who says: "There is much difficulty in understanding why hermaphrodite plants should ever have been rendered diocious." "We can, however, see that if a species were subjected to un-

1 "Fertilization of Flowers," English translation, p. 222

2 "The Different Forms of Flowers on Plants of the Same Species," p. 278, D. Appleton \& Co., New York. favorable conditions from severe competition with other plants, or from any other cause, the production of the male and female elements and the maturation of the ovules by the same individual might prove too great a strain on its powers, and the separation of the sexes would then be highly beneficial." As stated in a previous paragraph, many plum flowers are staminate in function as the fruit never develops. This being the case, it would seem an advantage for the pistil to become abortive and in some cases entirely suppressed. May it not be a step in a direction to prevent self-fertilization, which seems to occur quite commonly in some members of this order, or is it the direct action of climate as Darwin thought to be the case in the strawberry?

\section{LETTERS TO THE EDITOR.}

$*_{*}^{*}$ Correspondents are requested to be as brief as possible. The voriter's name is in all cases required as proof of good faith.

On request in advance, one hundred copies of the number containing his communication will be furnished free to any correspondent.

The editor will be glad to publish any queries consonant with the character of the journal.

\section{Total Heat Received by a Planet.}

IT may be as well to call attention to the shortest method of treating what seems to be the principal point at issue in the articles on "Sun-Heat and Orbital Eccentricity" and on "The Mean Distance of the Earth" in recent issues of Science.

We have simply for the amount of heat, $d h$, received by any planet in our system by radiation from the sun, in the infinitesimal time $d t$, on a definite area, say a square foot, of its vertically exposed surface,

$$
d h=\frac{c}{r^{2}} d t
$$

in which $c$ is a constant depending on the absolute radiation of the sun, which we suppose to be always the same.

But we have

$$
d t=: \frac{r_{2} d \theta}{k \sqrt{p}}
$$

in which $d t$ is expressed in terms of the day, $d \theta$ in the usual way, so that $180^{\circ}=\pi ; k$ being the Gaussian constant, depending on the mass or absolute attractive force of the sun, and $p$, the semiparameter, $=a\left(1-e^{2}\right)$.

Strictly, we must understand by $k$ the Gaussian constant $0.017202+$ multiplied by $\sqrt{1+\mu}$, in which

We have then

$$
\mu=\frac{\text { mass of planet }}{\text { mass of sun }} \text {. }
$$

$$
d h=\frac{c}{k \sqrt{p}} d \theta,
$$

and for the total heat received by radiation on the definite area in one revolution,

$$
\frac{2 c \pi}{k} \cdot \frac{1}{\sqrt{p}} \text {. }
$$

Now the major axis being supposed constant, $\vee \bar{p}$ is proportional to the minor axis. If then the eccentricity varies in a planetary orbit, the major axis remaining constant, the quantity of heat received by the planet in one revolution by radiation from the sun is inversely as the minor axis, if the size and mass of the planet and the mass and absolute radiation of the sun remain unchanged. Rev. Geo. M. SEarle.

Catholic University, Washington, D.C.

\section{A Peculiar Occurrence of Beeswax.}

AMONG the heterogenous collections of materials that are continually arriving at the National Museum for the purpose of idenbification, there were received some weeks ago, from Portland, Ciregon, samples of a material closely resembling, if not identical wi heeswax. Such it would have unhesitatingly been pronounced but for certain stated conditions relating to its mode of occurrence. 